\title{
Osteitic bone in recalcitrant chronic rhinosinusitis*
}

\author{
W.J.M. Videler ${ }^{1}$, C. Georgalas ${ }^{1}$, D.J. Menger ${ }^{1}$, N.J.M. Freling' ${ }^{2}$, C.M. van \\ Drunen $^{1}$, W.J. Fokkens ${ }^{1}$ \\ 1 Department of Otorhinolaryngology-Head and Neck Surgery, Academic Medical Centre \\ (AMC), Amsterdam, the Netherlands \\ 2 Department of Radiology, Academic Medical Centre (AMC), Amsterdam, the Netherlands
}

\begin{tabular}{|l|}
\hline Introduction: There is increasing interest in the underlying bone of the paranasal sinuses as \\
an important player in recalcitrant Chronic Rhinosinusitis. Close inspection of CT scans \\
often reveals areas of increased bone density and irregular thickening of the sinus walls. \\
This osteitic bone could at least partly explain, why inflammation of the mucosa persists. \\
Methods: We searched PubMed for all relevant studies, using the following text words: \\
chronic rhinosinusitis, sinusitis, bone, osteitis, osteomyelitis, histology, and treatment. \\
Cited references of retrieved articles were also examined. \\
Results: Background, available data, potential diagnostic options, treatment implications, \\
and suggestions for future research are discussed. \\
Conclusion: Osteitis is associated with CRS, however its role in the pathogenic process is \\
not well defined. More research is needed. \\
Key words: chronic rhinosinusitis, bone, osteitis
\end{tabular}

\section{INTRODUCTION}

Despite the evolution of Endoscopic Sinus Surgery (ESS), combined with optimal medical therapy, there is still a group of patients with recalcitrant Chronic RhinoSinusitis (CRS). The pathophysiology of this therapy-resistant form of CRS is poorly understood, but seems to be multi-factorial. Over the years, most CRS research has focused on the sinus mucosa. The immune response in this layer has been studied extensively, including the role of cellular infiltrates and local inflammatory markers. However, an overall understanding of the complex interplay of the diverse mucosal factors remains elusive. A new hypothesis reviewed by Harvey et al. focuses on biofilm (1). Biofilm continually presents antigen, resulting in chronic inflammation of the mucosa. It might also act as an unsurpassable barrier for innate host defense mechanisms as well as preventing antibiotics from reaching the causative microorganisms ${ }^{(2)}$. These characteristics of biofilm could potentially explain important clinical features of recalcitrant CRS.

However, beyond mucosa and biofilm, there is increasing interest in the underlying bone of the paranasal sinuses as an important player in recalcitrant CRS. This concept is based not only on the close anatomical relation between the mucosa and the underlying sinus bone, but also on radiological changes seen in patients with CRS. Close inspection of preoperative CT scans often reveals areas of increased bone density and irregular thickening of the sinus walls (see Figure 1). This osteitic bone could at least partly explain, why removal of sinus mucosa alone is sometimes not sufficient in the treatment of CRS, and why inflammation frequently recurs locally over the thickened bony areas ${ }^{(3-5)}$.

Interested in the role of osteitis in the pathogenesis of recalcitrant CRS, and surprised by the limited amount of data in literature, we conducted this review. The main aims were: to get a better insight in the available data, to identify potential diagnostic and therapeutic implications, and to put forward suggestions for future research. We searched PubMed for all relevant studies, using the following text words: chronic rhinosinusitis, sinusitis, bone, osteitis, osteomyelitis, histology, and treatment. Cited references of retrieved articles were also examined.

\section{WHAT IS THE STRUCTURE OF NORMAL BONE?}

Before we can address the potential contribution of osteitic bone in CRS, we need to first consider healthy bone. Although bone seems to be rigid in structure, it is in a state of constant change, both in shape and in form, as it reacts to a diversity of factors. This process known as bone remodeling is not specific for disease. It occurs continuously in healthy bone throughout life as well. Remodeling already starts during the embryonic development. A complex of invaginations of the nasal cavity into the surrounding bone creates the paranasal sinus system. Later in life remodeling plays an important role in response to various stimuli of which mechanical stress, fracture repair, and chronic inflammation are the most predominant ${ }^{(6)}$. The remodeling process requires a dynamic interaction between 


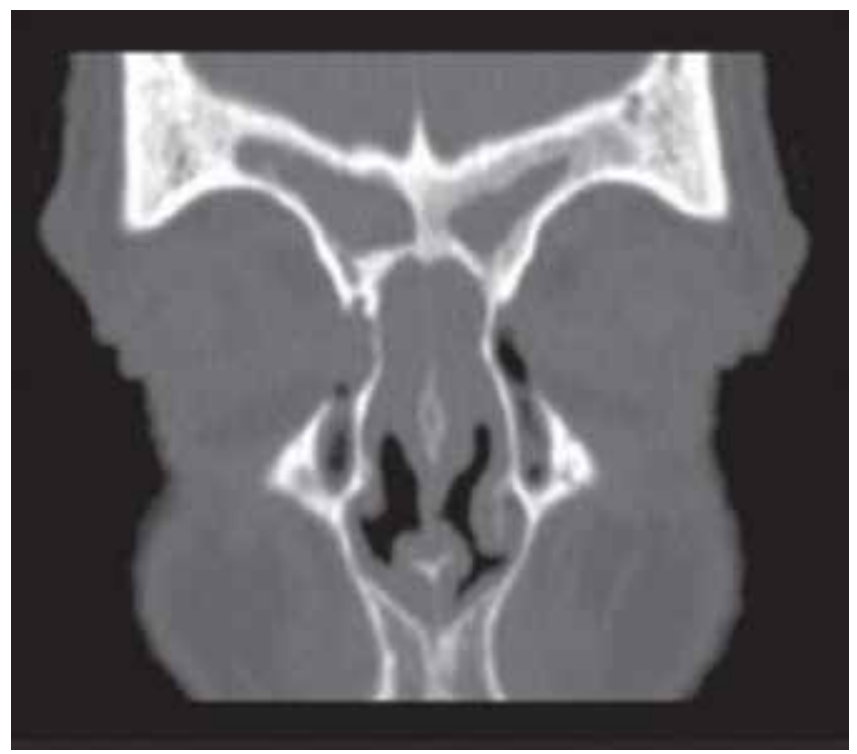

Figure 1. Osteitis of the left frontal sinus.

all histological players. A wide range of factors like steroids, hormones, prostaglandins, leukotrienes, growth factors, and inflammatory cytokines are all known to influence bone activity ${ }^{(7)}$. However, the exact mechanisms of bone remodeling are poorly understood.

The principle components of bone are matrix and different cells. The matrix is composed of collagen, hydroxyapatite, a small amount of proteoglycans, and non-collagenous proteins. The matrix also serves as a reservoir for calcium and phosphorus with a constant flux in and out of it. There are 3 main cell types. Osteoblasts, of mesenchymal origin, synthesize organic matrix components called osteoid (mainly type I collagen), play a role in the calcification process, and regulate osteoclast function. Osteoclasts, which are multinucleated giant cells derived from the hematopoietic system, are involved in the resorption of bone tissue. Osteocytes, which are found in lacunae within the matrix, are terminally differentiated osteoblasts. They become encased in the bone matrix during the process of bone formation. There is now an emerging consensus that osteocytes modulate signals arising from mechanical loading or inflammation, and by doing so, direct formation or resorption of bone tissue at a microscopic level. The molecular signaling pathways of osteocytes include nitric oxide, prostaglandins as well as cell-to-cell communication via gap junctions. Osteocytes also possess a diversity of receptors for various larger molecules like peptides, hormones and cytokines ${ }^{(8,9)}$.

Most flat bones of the skull have 2 layers of compact bone called plates, separated by a layer of spongy marrow. However, the flat bones lining the paranasal sinuses lack this marrow space ${ }^{(8,10)}$. Adult bone is characterized by the organization in osteons or haversian systems. These are complexes of concentric lamellae of bone surrounding a canal containing blood vessels, nerves, and loose connective tissue. The structure of bone is classified as either lamellar or woven. Woven bone is quickly formed, poorly organized tissue in which collagen fibers and mineral crystals are randomly arranged. Lamellar bone is slowly formed, highly organized bone consisting of parallel lamellae, of mineral crystals and collagen fibers ${ }^{(6)}$.

\section{WHAT ARE IMPORTANT FEATURES OF OSTEITIS IN CRS? \\ Terminology}

Different authors use different terms to discuss the same process of bone involvement in patients with recalcitrant CRS. Osteitis, osteomyelitis, hyperostosis, bone hyperplasia, bone remodeling, and neo-osteogenesis, all occur in literature. As there is no marrow space in the flat bones around the sinus, the term 'osteitis' is recommended to describe the process of involvement of bone surrounding the paranasal sinus in patients with CRS.

\section{Radiological features}

Conventional CT scanning is the most useful way to examine the paranasal sinuses. Besides demonstration of mucosal abnormalities, it is an accurate tool to evaluate bony structures of the paranasal system. On CT scan, osteitis appears as a thickened, irregular, heterogeneous lining of the sinus walls, which may be localized or affect all sinuses. The prevalence of the bony changes seen on CT scan varies from 2 to $64 \%{ }^{(5,11,12)}$. Lee et al. localized osteitic CT scan findings in their studied population of 121 CRS patients undergoing ESS, and showed that the ethmoid sinus was affected in $82 \%$, the sphenoid sinus in $64 \%$, and the maxillary sinus in $45 \%$ of the patients. The frontal sinus was not evaluated ${ }^{(5)}$. Traditional staging systems for CRS have focused on the degree of opacification of the sinuses and obstruction of the ostiomeatal complex, caused by mucosa or mucus. They do not evaluate changes of the bony surroundings of the sinuses ${ }^{(13,14)}$.

Besides the conventional CT scan, the use of other imaging modalities has been evaluated. MRI is more accurate than CT in assessing soft tissue, but lacks sufficient details for detecting bony changes. As such, it is not a modality likely to be useful for the assessment of osteitis ${ }^{(15)}$. Bone ${ }^{99}$ Technetium-MDP Single Photon Emission Computed Tomography (SPECT with ${ }^{99} \mathrm{mTc}$-MDP radiotracer) has been explored as an imaging modality in CRS ${ }^{(16-19)}$. The radiotracer is thought to absorb onto the hydroxyapatite of bone. Increased uptake of ${ }^{99} \mathrm{mTc}$ MDP usually reflects increase in blood flow and bone tissue turnover ${ }^{(17-19)}$. Javer et al. and Nishimura et al. found a positive correlation between clinical diagnosis of CRS and positive SPECT scan ${ }^{(16,17)}$. Jang et al. noted that greater radioisotope uptake in the ethmoid sinus portended a poorer postoperative outcome ${ }^{(18)}$. Catalano et al. were the first to show a correlation between SPECT and CT findings ${ }^{(19)}$. Despite these positive findings, SPECT is not used in routine clinical practice, because of the time consuming character of this investigation, exposure to radioactive material, costs and overall poor specificity. 
Table 1. Osteitis features reported in animal and human studies.

\begin{tabular}{|c|c|c|c|c|c|c|c|c|}
\hline author (year) & Material & $\mathrm{n}$ & $\begin{array}{l}\text { Periosteal } \\
\text { thickening }\end{array}$ & $\begin{array}{l}\text { Osteoclast } \\
\text { resorption }\end{array}$ & $\begin{array}{l}\text { Osteoblast } \\
\text { neogenesis }\end{array}$ & $\begin{array}{c}\text { Haversian canal } \\
\text { changes }\end{array}$ & Fibrosis & infiltrate \\
\hline \multicolumn{9}{|l|}{ ANIMAL } \\
\hline Westrin (1992) & $\begin{array}{l}\text { B.fragilis; } \\
\text { maxillary sinus }\end{array}$ & 21 & + & + & + & - & - & - \\
\hline Norlander (1992) & $\begin{array}{l}\text { S.pneumoniae/B.fragilis; } \\
\text { maxillary sinus }\end{array}$ & 30 & + & + & + & - & + & - \\
\hline Bolger (1997) & $\begin{array}{l}\text { P.aeruginosa; } \\
\text { maxillary sinus }\end{array}$ & 33 & - & + & + & - & + & - \\
\hline Perloff (2000) & $\begin{array}{l}\text { P.aeruginosa; } \\
\text { maxillary sinus }\end{array}$ & 19 & - & + & - & + & + & + \\
\hline Khalid (2002) & $\begin{array}{l}\text { P.aeruginosa/S.aureus; } \\
\text { maxillary sinus }\end{array}$ & 29 & - & + & + & + & + & + \\
\hline Artunes (2007) & $\begin{array}{l}\text { P.aeruginosa; } \\
\text { maxillary sinus }\end{array}$ & 26 & + & + & + & - & - & + \\
\hline \multicolumn{9}{|l|}{ HUMAN } \\
\hline Tolsdorf (1983) & inferior turbinate & $>200$ & + & + & + & - & + & + \\
\hline Tovi (1992) & sinus wall; sequesters & 4 & + & - & + & - & + & + \\
\hline Biedlingmaier (1996) & middle turbinate & 38 & + & + & + & - & - & + \\
\hline Kennedy (1998) & ethmoid & 33 & - & + & + & - & + & + \\
\hline Giacchi (2001) & ethmoid & 19 & + & + & + & - & + & + \\
\hline Lee (2006) & ethmoid, maxillary & 12 & + & - & + & - & + & - \\
\hline Cho (2006) & ethmoid & 39 & + & + & + & - & + & + \\
\hline
\end{tabular}

\section{Histological features: animal data}

Most animal data on the role of bone in CRS are based on rabbit studies, because of the ease to surgically access the maxillary sinuses, the ability to occlude the sinuses, and the reliability to induce infections ${ }^{(4,20-24)}$. Westrin et al. used this animal model to study anaerobic maxillary sinus mono-infections. They induced infection in the maxillary sinus with Bacteroides fragilis and demonstrated histological changes of the affected maxillary sinus bones ${ }^{(20)}$. Other authors modified this rabbit model, inoculating different pathogens and evaluating histological features of both mucosa and bone tissue. Animal studies have revealed the following histological changes in bone tissue after experimentally induced sinusitis: 1) osteoclastic bone resorption ${ }^{(4,20-24)}$; 2) osteoblastic bone deposition ${ }^{(20-24)} ; 3$ ) widening of the haversian system ${ }^{(4,23)}$; 4) involvement of the periosteum $^{(20,24,25)}$; 5) fibrosis ${ }^{(4,21-23)}$; 6) cellular infiltrates ${ }^{(4,23,24)}$. Results are demonstrated in Table 1.

Besides these osteitis features, animal models have contributed to other observations that showed involvement of bone tissue in sinusitis. Bolger et al. demonstrated bony changes as early as 4 days after infection with Pseudomonas aeruginosa ${ }^{(22)}$. Perloff et al. were able to show that bone changes caused by $P$. aeruginosa infection in the presence of surgical intervention could spread not only to the adjacent bone, but also within the bone to the opposite sinonasal complex. They found that bone, harvested from the inoculated side and transplanted to the non-infected side, could induce mucosal infection. However, they discussed that the bone exposure with periosteal elevation was more extensive than would occur with conservative endoscopic procedures and would be more comparable to what may happen during an open surgical intervention for CRS ${ }^{(4)}$. Two studies observed widening of the spaces of the haversian system through osteoclastic resorption, fol- lowed by increased vascularization during the initial phase of disease. These changes were also discovered in the non-inoculated contralateral sinonasal complex, suggesting a potential route for spread of infection through the enlarged canals. In contrast to the osteoclastic reaction seen early in disease, late-stage disease is characterized by subsequent appositional and intra-membranous bone formation, as well as fibrosis of the haversian systems ${ }^{(4,23)}$. A possible scenario explaining the spread of inflammation from the primary infected site to distant locations is formulated by Khalid et al.: disease of the sinus mucosa; entrance of the inflammation and infectious agents into the underlying bone; activation of the remodeling process; access to the vascular network; spread through the bone to the contralateral side, possibly via vascular network or haversian canals ${ }^{(23)}$.

A limitation of all the animal studies is the follow-up period. In most studies, animals were sacrificed 2-4 weeks after inoculation ${ }^{20-22,24)}$. Khalid's study has a follow-up of 7-9 weeks ${ }^{(23)}$. Perloff et al. transplanted a bone fragment in all the animals 6 weeks after inoculation from the infected side to a submucosal pocket on the control side; after 13 weeks the animals were sacrificed and samples investigated ${ }^{(4)}$.

\section{Histological features: human data}

Similar histological findings have been reported in bony specimens obtained from human patients with CRS. Early reports on human nasal turbinates showed histological changes of both mucosa and bone. The inflammatory changes of the turbinate bone have been associated with a possible role in recalcitrant CRS ${ }^{(26,27)}$. Tovi et al. presented 4 cases of patients with symptoms of CRS with suppuration and thickening of the bony walls of the sinus. Histological evaluation showed periosteal reaction along with osteoblast proliferation, new bone formation and fibrosis ${ }^{(28)}$. 


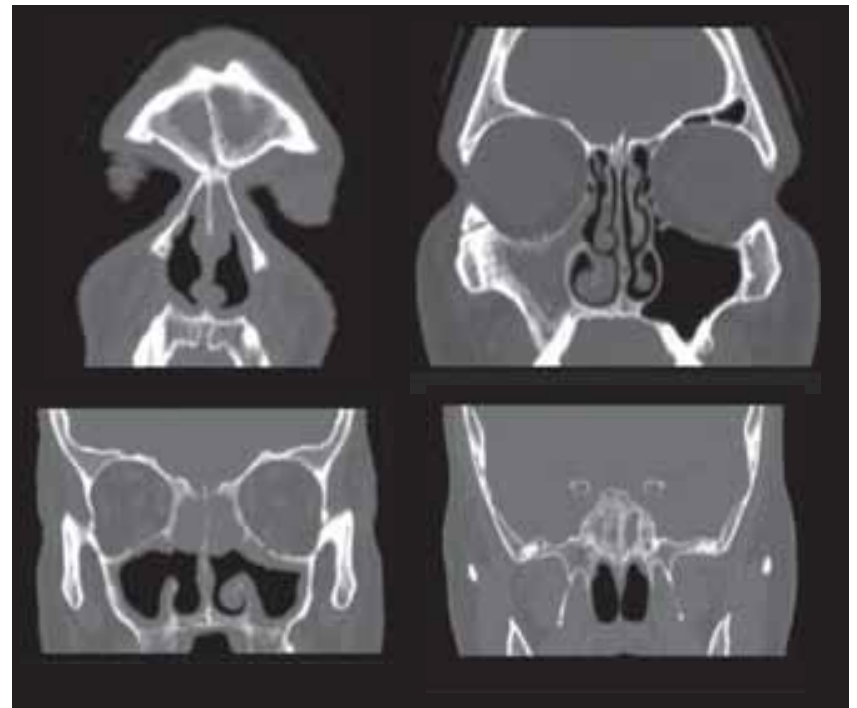

Figure 2. Osteitis of the frontal sinus, right maxillary sinus, sphenoid sinus, and lamina papyracea (clock-wise).

There are 4 studies reporting on prospective data of histological changes of sinus bone in humans with CRS. The first investigation was performed by Kennedy et al., using tetracycline labeling to evaluate remodeling of ethmoid bone. Tetracycline labeling demonstrated higher bone activity with increased bone resorption and marked neo-osteogenesis in sinusitis patients that was not seen in the controls. Histological findings including new bone formation, fibrosis, and the presence of inflammatory cells, suggested that this increased bone activity could be associated with $\mathrm{CRS}^{(3)}$.

Giacchi et al. found periosteal thickening in all specimens of ethmoid bone of CRS patients compared with samples of patients undergoing a cerebrospinal leak repair. They demonstrated a varying degree of increased osteoblastic-osteoclastic activity, as shown by the disruption of organized lamellar bone and formation of immature woven bone. In addition, the extent of bony remodeling was found to correlate with the severity of disease, with more advanced bony changes associated with higher Lund-Mackay scores on CT. More advanced pathological changes included intralacunar fibrosis ${ }^{(29)}$.

Lee et al. found osteitis in 53\% in their histology samples. Interestingly, the incidence of pathologically proven osteitis was $6.7 \%$ in those undergoing primary surgery, but increased to $58 \%$ in patients having revision ESS. They also demonstrated reactive bone by using light microscopy demonstrating new bone formation in the form of increased uncalcified matrix (osteoid) secreted by osteoblasts and woven bone formation ${ }^{(5)}$. Cho et al. demonstrated periosteal thickening, osteoblastic-osteoclastic activity, and woven bone formation in CRS patients and compared these results with CT scan findings ${ }^{\left({ }^{(30)} \text {. }\right.}$

To summarize, the most important features found in human samples of osteitic bone in sinusitis patients are: 1) periosteal changes ${ }^{(5,27-30)} ; 2$ ) osteoclast proliferation and bone resorption $(3,27,29,30)$; 3) new bone formation ${ }^{(3,5,27-30)}$; 4) fibrosis ${ }^{(3,5,28-30)}$; 5) cellular infiltrates ${ }^{(3,27-30)}$; see Table 1.

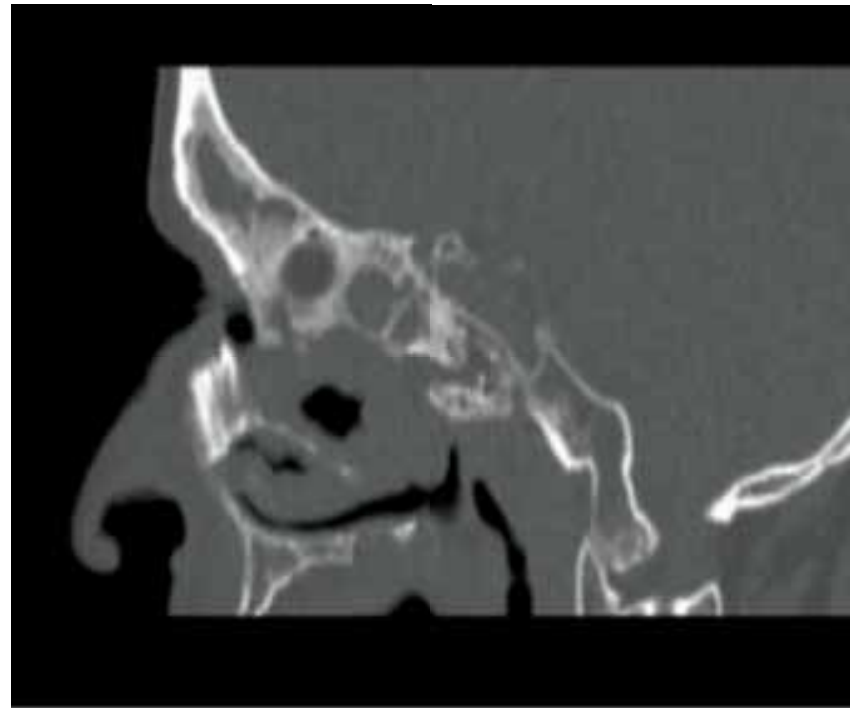

Figure 3. Osteitis along the skull base.

POSSIBLE MECHANISMS: INFECTION VERSUS INFLAMMATION

Infection: role of bacteria

Some authors discuss that the rigid, three-dimensional structure of bone that exists even in the absence of cellular components, could become a honeycomb where bacteria may reside for extended periods of time, out of reach of immunological cells and antibiotics ${ }^{(3)}$. On first hand this direct bacterial invasion of bone appears a logic model. It could help to explain the clinical observation that removal of only the overlying diseased mucosa frequently results in recurrence and persistence of CRS, whereas debridement of the underlying bone often resolves disease ${ }^{(3,4,31)}$. Nair et al. suggested 3 possibilities on the role of bacteria: 1) bacteria directly destroy the noncellular components of bone by liberating acid and proteases, 2) bacteria promote cellular processes that stimulate the degradation of bone, or 3) bacteria inhibit the synthesis of bone matrix ${ }^{(7)}$. However, to date no group was able to demonstrate bacteria in bone of the paranasal sinuses, and whether bacteria induce bony remodeling because of associated inflammation or whether they truly infect bone is unknown ${ }^{(22,23,32)}$.

\section{Inflammation: role of virulence factors}

Some studies have reported on the intracellular presence of bacteria in the epithelial cells of the middle meatus mucosa (33,34). These intracellular colonies may represent a reservoir for recurrent episodes of CRS that are protected from host defense mechanisms and antibiotic treatment. In literature on osteomyelitis of the long bones, evidence is emerging that staphylococci are facultative intracellular pathogens. They have been demonstrated in the host osteoblasts in chronic osteomyelitis cases. It is suggested that they also produce exopolysaccharide networks for protection, which may also explain inaccessibility to antibiotic treatment ${ }^{(35-37)}$. To date these findings could not be confirmed in inflamed bone of the paranasal sinuses. 
Biofilms can also serve as a reservoir for bacteria. Secretion of various soluble inflammatory factors from these reservoirs could feed the osteitic reaction in the underlying bone. The release of mediators, particularly those of the arachidonic acid pathway, has been postulated by Bolger et al. and CayeThomasen et al. to be the stimulus for bone remodeling in sinusitis animal models by modulating osteoclastic and osteoblastic activity ${ }^{(22,38)}$.

There is an increasing number of inflammatory factors known to play a role in normal bone remodeling and osteitis. These factors can be divided into circulating or local factors. Examples of circulating factors are: parathyroid hormone (PTH), 1,25-dihydroxy vitamin D, calcitonin, estradiol, and other hormones. Local factors are prostaglandins, leukotrienes, pro-inflammatory cytokines like IL-1, IL-6, Tumor Necrosis Factor (TNF- $\alpha$ ), and growth factors. Another division can be made between host and bacterial factors. Bacterial factors are diverse and include LPS, teichoic acids, and other cell wall components ${ }^{(7)}$. A third attempt to make a division, is based on the effect of the factors on bone. Bone resorption is known to be stimulated by cytokines like IL-1, IL- 6 , IL-11, TNF- $\alpha$, and PTH, 1,25-dihydroxy vitamin D, and Prostaglandin-E (PGE). Bone apposition is triggered by calicitonin, IL-4, IL-13, IL-18, INF- $\gamma$, and Osteoprotegerin $(\mathrm{OPG}){ }^{(39,40)}$. A problem with this classification is that a number of molecules have both capacities. Ishino et al. performed studies in ethmoid bone of patients with CRS. They found that osteoclast differentiation and activity was controlled by a wide range of molecules (IL-1 $\beta$, IL-6, IL-8, TNF- $\alpha$, Macrophage Colony-Stimulating Factor (M-CSF) and specific proteins like Receptor Activator of Nuclear Factor (NF)- $\kappa B$ Ligand (RANKL), and OPG) ${ }^{(41,42)}$. Bone Morphogenetic Protein (BMP) also seems to play an important role ${ }^{(43)}$. The BMP family has originally been described, as the name suggests, in relationship to bone morphogenesis and again this could well be related to the sinonasal changes in bone formation seen in CRS and nasal polyposis. This paragraph is not intended to be complete. Much remains to be learned about the role of the diverse factors in bone, particularly in humans.

\section{WHAT TO DO IN PATIENTS WITH CRS AND OSTEITIC BONE? \\ Imaging}

The CT scan is the modality of choice to evaluate sinusitis and osteitis features in patients with CRS. Osteitis is in most cases a radiological diagnosis. However, both otorhinolaryngologists and radiologists tend to overlook CT scan evidence of bone changes in chronic osteitic sinusitis. Differentiating these changes from other bone diseases such as Paget's disease or metabolic bone disease may not be possible in the absence of relevant clinical data. Comparable abnormalities of bone can also be observed after sinus surgery or radiation therapy (44). Although correlations between sinonasal complaints of patients and mucosal abnormalities seen on CT are weak or have failed ${ }^{(45-47)}$, there are reports showing that patients with bony changes on $\mathrm{CT}$ scan may have a poorer surgical outcome than those without these bony changes ${ }^{(12)}$.

\section{Medical therapy}

Evidence of concurrent osteitis in CRS patients has led to the introduction of new therapeutic approaches. Some authors have advocated the use of long-term intravenous antibiotics in an attempt to eradicate bone involvement, analogous to the treatment for osteomyelitis. Tovi et al. treated the osteitis of their CRS patients with surgical debridement followed by $3-8$ weeks of culture directed intravenous antibiotics. They reported favorable outcomes ${ }^{(28)}$. A problem of systemic, medical treatment could be the relatively avascular and ischemic conditions of the infected region, which makes antibiotic penetration into the osteitic bone difficult. In addition, fibrosis of the haversian canals can obstruct distribution of medication in the later phase of disease. While nearly all antibiotics penetrate bone, actual bone levels are usually low, approximately $10-30 \%$ of the serum level. Serum bactericidal titers need to be several times higher than minimal bactericidal concentration for susceptibility in the bone infection. This has resulted in an axiom in the management of osteomyelitis of the long bones that a serum bactericidal titer of 1:8 constitutes effective antimicrobial therapy ${ }^{(48)}$. It is assumed that a similar increase in dosage is needed to effectively treat osteitis in recalcitrant CRS, but there are no sufficient data in literature to support this.

Without evidence of an active bacterial infection in the sinus bone, the use of prolonged antibiotics is difficult to justify. Assuming that the inflammatory pathway and not the infectious one is more important in the bone involvement in CRS, other medical regimes like long-term systemic steroids or macrolide treatment could be considered. Macrolides are antibiotics known to have anti-inflammatory properties, besides their bacteriostatic effects. Several studies have shown macrolides to inhibit interleukin gene expression for IL-6 and IL-8, and to inhibit the expression of intercellular adhesion molecule, essential for the recruitment of inflammatory cells ${ }^{(49-53)}$. Placebocontrolled studies should be performed to further establish the efficacy of macrolides in CRS and the effects on osteitis. Studying long-term administration of antibiotics, the possibility of pathogen resistance should always be kept in mind.

The role of topical application of antibiotics is still under discussion. Few studies have explored the therapeutic role of topical nasal antimicrobials in patients with CRS. Several uncontrolled studies indicate that the topical application of antibiotics has a beneficial effect ${ }^{(24,54-57)}$. Others have found that nasal irrigation is useful, but addition of antibiotics represents no supplementary advantage ${ }^{(58-61)}$. Goh and Goode and Elliott et al. reviewed the limited data. Their overall conclusion was that the role of nasal antimicrobial therapy, although promising, was not established ${ }^{(62,63)}$. 
Table 2. Examples of CT grading systems for severity of osteitis.

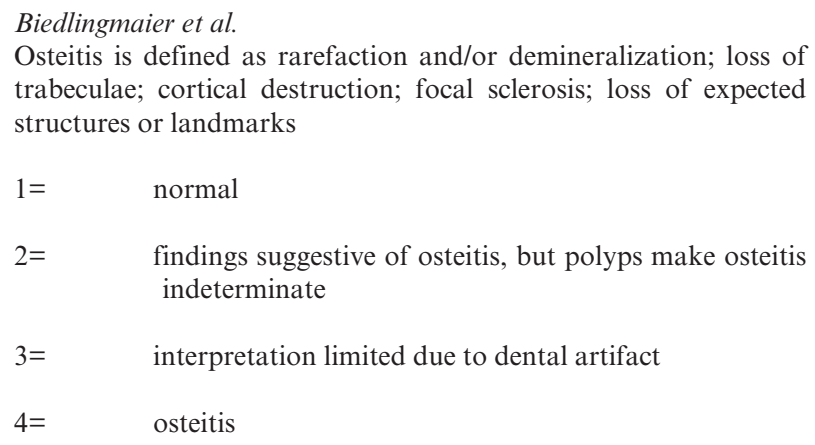

Lee et al.
Osteitis thickness measurement
Mild: $\quad 3 \quad \mathrm{~mm}$
Moderate: $4-5 \mathrm{~mm}$
Severe: $\quad>5 \mathrm{~mm}$

Table 3. Three-point radiology scale.

\begin{abstract}
Kim et al.
$1 \quad$ Maxillary sinus: posterolateral bony wall in the axial setting with the greatest dimension of maxillary sinus.

2 Mean bony thickness of 3 randomly selected ethmoid septa.

3 Mid-point of middle turbinate in the axial section showing the largest middle turbinate.

The radiologist registered hyperostosis when he measured values $>3$ standard deviations beyond the range of normal reference data.
\end{abstract}

Table 4. Examples of histological grading systems.

\begin{tabular}{|c|c|}
\hline \multicolumn{2}{|c|}{ Biedlingmaier et al. } \\
\hline 0 & normal \\
\hline 1 & periosteal thickening \\
\hline 2 & $\begin{array}{l}\text { periosteal thickening, osteoblastic-osteoclastic activity, } \\
\text { bone resorption and/or remodeling }\end{array}$ \\
\hline 3 & $\begin{array}{l}\text { periosteal thickening, osteoblastic-osteoclastic activity, } \\
\text { bone resorption and/or remodeling and wide osteoid } \\
\text { seams }\end{array}$ \\
\hline 4 & frank osteomyelitis, leukocytes and bone destruction \\
\hline \multicolumn{2}{|c|}{ Cho et al. } \\
\hline 0 & normal \\
\hline 1 & minimal periosteal thickening \\
\hline 2 & $\begin{array}{l}\text { mild periosteal thickening with osteoblastic-osteoclastic } \\
\text { activity }\end{array}$ \\
\hline 3 & $\begin{array}{l}\text { moderate periosteal thickening with wide osteoid seam } \\
\text { and osteoblastic-osteoclastic activity }\end{array}$ \\
\hline 4 & severe periosteal thickening and marrow formation \\
\hline \multicolumn{2}{|c|}{ Antunes et al. } \\
\hline 0 & no inflammation \\
\hline 1 & mild periosteal thickening \\
\hline 2 & moderate periosteal thickening and osteoblastic rimming \\
\hline 3 & $\begin{array}{l}\text { periosteal thickening, osteoid seams, osteoblastic rim- } \\
\text { ming }\end{array}$ \\
\hline
\end{tabular}

Surgery

In Messenklinger's original teaching, the primary goal of reestablishing ventilation and drainage through natural sinus ostia was based on the expectation that even extensive pathological mucosa change would reverse itself with the reestablishment of normal drainage. This seems insufficient in resolving the problem of recalcitrant CRS with osteitis. Remnants of diseased bone may serve as a constant nidus for inflammation, inducing recurrent edema and hypertrophy of the overlying mucosa. The aim of surgery in these recalcitrant cases should be the removal of all the diseased bone and granulation tissue, and the facilitation of adequate perfusion of the sinuses with antibiotics administered systemically ${ }^{(64)}$. Our group reported symptom reduction of a group of therapy resistant patients after Denker's procedure ${ }^{(65,66)}$. Rhinorrhea, nasal obstruction, as well as facial pain and quality of life improved. Radical surgery does not seem to be of great benefit when the main complaints are reduced olfactory perception or asthma. Discussion about the removal of landmarks like the middle turbinate is ongoing. But at the end what is the need of an inflamed landmark being a nidus of disease? When studying radical surgery in recalcitrant CRS, we should always be aware of the fact that radical surgery itself can also be a trigger for osteitic bone reaction ${ }^{(44)}$.

\section{SUGGESTIONS FOR FUTURE RESEARCH \\ Pitfalls}

There is an increasing pressure on medical practitioners to use evidence-based measures. Concerning the role of osteitis in recalcitrant CRS there is a lot of research still to be done. Although it is tempting to extrapolate scientific results from limited studies to the patient, this would be premature at present. All investigations represent an oversimplification of reality. Only a very limited group of pathogens has been studied in rabbit models. Bone was exposed to bacteria during sinus occlusion and harvesting, which means substantial manipulation. We only found 7 reports on human bone material. Only 3 were placebo controlled. When designing studies we always should choose the most optimal control tissue. Rinia et al. discuss the importance of useful control tissue in their review on nasal polyps, and put a question mark to the use of inferior and middle turbinate mucosa as a control for nasal polyps ${ }^{(67)}$. This is also an important reminder in the choice of a useful control in osteitic bone research. Is a middle or inferior turbinate useful control tissue, or is the bone structure and histological reaction significantly different from the sinus wall? Ideal control tissue would be bone tissue of the same paranasal area from patients undergoing surgery for non-inflammatory disease like adenoma of the pituitary gland or repair of a cerebrospinal leak. Further experimental studies should be designed to identify the best control tissue.

\section{Definition}

To date no uniform osteitis definition is available. It is not part of the CRS definition of the American Academy of Otolaryngology and Head and Neck Surgery, nor is it part of 
the latest version of the EPOS $^{3}$ document ${ }^{(68,69)}$. Without a definition, including both radiological and histological features, results are hard to compare, and scientific conclusions are hard to draw.

\section{Radiological staging}

As mentioned before, radiologic staging systems tend to focus on mucosal changes and do not incorporate changes seen in the surrounding bone ${ }^{(10,13,14)}$. Biedlingmaier et al. and Lee et al. were the first to define radiologic osteitis as mentioned before (see Table 2) ${ }^{(5,27)}$. Cho et al. developed a method to determine bone density on $\mathrm{CT}$ in patients with CRS, using a line profile through the ethmoid bulla and quantifying bone density using the Hounsfield scale ${ }^{(30,70)}$. Air is assigned a value of -1000 , water a value of 0 (zero) and bone of +1000 . They found a correlation between bone changes and the Lund-MacKay score and they concluded that CT densities could be used as an objective parameter of bone remodeling in patients suffering from CRS. More research needs to be done to evaluate if the Hounsfield unit is of value in staging osteitis in recalcitrant CRS. Another attempt to objectify osteitic changes on CT was performed by Kim et al. ${ }^{(12)}$. They measured 3 standardized reference points on CT (see Table 3) and the radiologist registered hyperostosis when he measured values $>3$ standard deviations beyond the range of normal, self-obtained reference data. A possible combination of osteitic characteristics with the use of millimeter measurements or Hounsfield-Units, could make a osteitis grading system more objective. When developing a grading scale, more questions remain. For example do we evaluate every sinus separately, like Lund-Mackay, and which locations of the sinus bone do we measure?

\section{Histological exploration}

In favor of histological research, microscopic findings should also be more defined. The investigating groups use different ways to fixate samples, diverse methods of decalcification and varying protocols for tissue embedding. Most groups used H\&E staining to identify inflammation, bone cells, while differentiation between woven and non-woven bone is possible by means of polarization microscopy. In our opinion, the most useful histological grading system used so far is that described by Biedlingmaier et al. (see Table 4) ${ }^{(27)}$.

The following aspects in histological research on osteitic bone in CRS should incorporate at least the following items: changes of the periosteum, number of osteoblasts, numbers of osteoclasts, changes seen in the haversian system, and fibrosis. Furthermore determination of cell types in the leukocytic infiltrates appears to be useful, but has not been attempted so far. These microscopic findings could be combined with investigations on inflammatory markers like TGF- $\beta$ which is one of the important growth regulatory factors in bone matrix. A long list of other factors worthwhile to investigate could be: IL-1, IL-4, IL-6, IL-8, TNF- $\alpha$, M-CSF, RANKL, alkaline phosphatase (ALP), OPG, fibroblast growth factor (FGF), MCP-1, par- athyroid hormone, 1,25(OH)2 vitamin $\mathrm{D}$, calcitonin, glucocorticoids, cortisol, oestrogens, PGE2, IFN- $\gamma$, insulin like growth factor-1, LPS, teichoic acids, lipid A associated proteins, cell wall components, nitric oxide, MCP-1, TGF $\alpha$, TGF $\beta$, plateletderived growth factor, collagen type I and osteocalcin ${ }^{(39-42,71)}$.

\section{REFERENCES}

1. Harvey RJ, Lund VJ. Biofilms and chronic rhinosinusitis: systematic review of evidence, current concepts and directions for research. Rhinology. 2007; 45: 3-13.

2. Post JC, Stoodley P, Hall-Stoodley L, Ehrlich GD. The role of biofilms in otolaryngologic infections. Curr Opin Otolaryngol Head Neck Surg. 2004; 12: 185-190.

3. Kennedy DW, Senior BA, Gannon FH, Montone KT, Hwang P, Lanza DC. Histology and histomorphometry of ethmoid bone in chronic rhinosinusitis. Laryngoscope. 1998; 108: 502-507.

4. Perloff JR, Gannon FH, Bolger WE, Montone KT, Orlandi R, Kennedy DW. Bone involvement in sinusitis: an apparent pathway for the spread of disease. Laryngoscope. 2000; 110: 2095-2099.

5. Lee JT, Kennedy DW, Palmer JN, Feldman M, Chiu AG. The incidence of concurrent osteitis in patients with chronic rhinosinusitis: a clinicopathological study. Am J Rhinol. 2006; 20: 278282.

6. Martin RB, Burr DB, Sharkey NA. Skeletal tissue mechanics. New York: Springer-Verlag, 1998.

7. Nair SP, Meghji S, Wilson M, Reddi K, White P, Henderson B. Bacterially induced bone destruction: mechanisms and misconceptions. Infect Immun. 1996; 64: 2371-2380.

8. Erlebacher A, Filvaroff EH, Gitelman SE, Derynck R. Toward a molecular understanding of skeletal development. Cell. 1995; 80: 371-378.

9. Noble BS, Reeve J. Osteocyte function, osteocyte death and bone fracture resistance. Mol Cell Endocrinol. 2000; 159: 7-13.

10. Kocak M, Smith TL, Smith MM. Bone involvement in chronic rhinosinusitis. Curr Opin Otolaryngol Head Neck Surg. 2002; 10 : 49-52.

11. Richtsmeier WJ. Top 10 reasons for endoscopic maxillary sinus surgery failure. Laryngoscope. 2001; 111(11 Pt 1): 1952-1956.

12. Kim HY, Dhong HJ, Lee HJ, et al. Hyperostosis may affect prognosis after primary endoscopic sinus surgery for chronic rhinosinusitis. Otolaryngol Head Neck Surg. 2006; 135: 94-99.

13. Lund VJ, Mackay IS. Staging in rhinosinusitus. Rhinology. 1993; 31: 183-184.

14. Lund VJ, Kennedy DW. Staging for rhinosinusitis. Otolaryngol Head Neck Surg. 1997; 117: S35-S40.

15. Larson TL. Sinonasal inflammatory disease: pathophysiology, imaging, and surgery. Semin Ultrasound CT MR. 1999; 20: 379390 .

16. Javer AR, Stevens HE, Stillwell M, Jafar AM. Efficacy of nuclear scintigraphy in the diagnosis and management of sinusitis. $\mathbf{J}$ Otolaryngol. 1996; 25: 375-382.

17. Nishimura T, Iizuka T. Diagnostic value of spect bone scintigraphy for odontogenic maxillary sinusitis. Clin Nucl Med. 2001; 26: 509-514.

18. Jang YJ, Koo TW, Chung SY, Park SG. Bone involvement in chronic rhinosinusitis assessed by $99 \mathrm{mTc}-\mathrm{MDP}$ bone SPECT. Clin Otolaryngol Allied Sci. 2002; 27: 156-161.

19. Catalano PJ, Payne SC, Choi E, Shah R. Correlation between computed tomography and bone single photon emission-computed tomography scintigraphy in patients with chronic rhinosinusitis. Am J Rhinol. 2007; 21: 433-438.

20. Westrin KM, Norlander T, Stierna P, Carlsoo B, Nord CE. Experimental maxillary sinusitis induced by Bacteroides fragilis. A bacteriological and histological study in rabbits. Acta Otolaryngol. 1992; 112: 107-114.

21. Norlander T, Forsgren K, Kumlien J, Stierna P, Carlsoo B. Cellular regeneration and recovery of the maxillary sinus mucosa. An experimental study in rabbits. Acta Otolaryngol Suppl. 1992; 492: 33-37. 
22. Bolger WE, Leonard D, Dick EJ, Jr., Stierna P. Gram negative sinusitis: a bacteriologic and histologic study in rabbits. Am J Rhinol. 1997; 11: 15-25.

23. Khalid AN, Hunt J, Perloff JR, Kennedy DW. The role of bone in chronic rhinosinusitis. Laryngoscope. 2002; 112: 1951-1957.

24. Antunes MB, Feldman MD, Cohen NA, Chiu AG. Dosedependent effects of topical tobramycin in an animal model of Pseudomonas sinusitis. Am J Rhinol. 2007; 21: 423-427.

25. Norlander T, Westrin KM, Stierna P. The inflammatory response of the sinus and nasal mucosa during sinusitis: implications for research and therapy. Acta Otolaryngol Suppl. 1994; 515: 38-44.

26. Tolsdorff $P$. Osteomyelitis of the turbinates and its significance in chronic sinusitis. HNO. 1983; 31: 314-319.

27. Biedlingmaier JF, Whelan P, Zoarski G, Rothman M. Histopathology and CT analysis of partially resected middle turbinates. Laryngoscope. 1996; 106(1 Pt 1): 102-104.

28. Tovi F, Benharroch D, Gatot A, Hertzanu Y. Osteoblastic osteitis of the maxillary sinus. Laryngoscope. 1992; 102: 426-430.

29. Giacchi RJ, Lebowitz RA, Yee HT, Light JP, Jacobs JB Histopathologic evaluation of the ethmoid bone in chronic sinusitis. Am J Rhinol. 2001; 15: 193-197.

30. Cho SH, Min HJ, Han HX, Paik SS, Kim KR. CT analysis and histopathology of bone remodeling in patients with chronic rhinosinusitis. Otolaryngol Head Neck Surg. 2006; 135: 404-408.

31. Chiu AG. Osteitis in chronic rhinosinusitis. Otolaryngol Clin North Am. 2005; 38: 1237-1242.

32. Meltzer EO, Hamilos DL, Hadley JA, Lanza DC, Marple BF, Nicklas RA, et al. Rhinosinusitis: Establishing definitions for clinical research and patient care. Otolaryngol Head Neck Surg. 2004; 131(6 Suppl): S1-62.

33. Clement S, Vaudaux P, Francois $P$, et al. Evidence of an intracellular reservoir in the nasal mucosa of patients with recurrent Staphylococcus aureus rhinosinusitis. J Infect Dis. 2005; 192: 1023-1028.

34. Plouin-Gaudon I, Clement S, Huggler E, et al. Intracellular residency is frequently associated with recurrent Staphylococcus aureus rhinosinusitis. Rhinology. 2006; 44: 249-254.

35. Ellington JK, Harris M, Hudson MC, Vishin S, Webb LX, Shererts R. Intracellular Staphylococcus aureus and antibiotic resistance: implications for treatment of staphylococcal osteomyelitis. J Orthop Res. 24, 87-93.

36. Bosse MJ, Gruber HE, Ramp WK. Internalization of bacteria by osteoblasts in a patient with recurrent, long-term osteomyelitis. A case report. J Bone Joint Surg Am. 87, 1343-1347.

37. Webb LX, Wagner W, Caroll D, Tyler H, Coldren F, Martin E. Osteomyelitis and intraosteoblastic Staphylococcus aureus. J Surg Ortop Adv. 16, 73-78

38. Caye-Thomasen P, Hermansson A, Tos M, Prellner K. Bone modeling dynamics in acute otitis media. Laryngoscope 1999; 109: 723-9.

39. Lorenzo JA. The role of cytokines in the regulation of local bone resorption. Crit Rev Immunol 1991; 11: 195-213.

40. Raisz LG. Physiology and pathophysiology of bone remodeling. Clin Chem 1999; 45(8 Pt 2): 1353-8.

41. Ishino T, Yajin K, Takeno S, Furukido K, Takumida M, Hirakawa K. Human osteoclast maturation from bone marrow cells co-cultured with osteoblast from ethmoid sinus. Rhinology. 2003; 41: 49-53.

42. Ishino $\mathrm{T}$, Yajin $\mathrm{K}$, Takeno $\mathrm{S}$, Furukido $\mathrm{K}$, Hirakawa $\mathrm{K}$. Establishment of osteoblast culture from human ethmoidal sinus. Auris Nasus Larynx. 2003; 30: 45-51.

43. Harris SE, Bonewald LF, Harris MA, et al. Effects of transforming growth factor beta on bone nodule formation and expression of bone morphogenetic protein 2, osteocalcin, osteopontin, alkaline phosphatase, and type I collagen mRNA in long-term cultures of fetal rat calvarial osteoblasts. J Bone Miner Res. 1994; 9: $855-863$

44. Moreno PM, Meseguer DH. Bone changes after maxillary sinus surgery: an experimental scanning electron microscopy study. J Laryngol Otol. 2008; 122: 470-475.

45. Bhattacharyya T, Piccirillo J, Wippold FJ. Relationship between patient-based descriptions of sinusitis and paranasal sinus computed tomographic findings. Arch Otolaryngol Head Neck Surg. 1997; 123: 1189-1192.

46. Holbrook EH, Brown CL, Lyden ER, Leopold DA. Lack of significant correlation between rhinosinusitis symptoms and specific regions of sinus computer tomography scans. Am J Rhinol. 2005; 19: 382-387

47. Wabnitz DA, Nair S, Wormald PJ. Correlation between preoperative symptom scores, quality-of-life questionnaires, and staging with computed tomography in patients with chronic rhinosinusitis. Am J Rhinol. 2005; 19: 91-96.

48. Salvati E, Small R, Brause B, et al. Infections associated with orthopedic devices. Boca Raton, 1984.

49. Suzuki H, Shimomura A, Ikeda K, Furukawa M, Oshima T, Takasaka T. Inhibitory effect of macrolides on interleukin- 8 secretion from cultured human nasal epithelial cells. Laryngoscope. 1997; 107(12 Pt 1): 1661-1666.

50. Nonaka M, Pawankar R, Saji F, Yagi T. Effect of roxithromycin on IL-8 synthesis and proliferation of nasal polyp fibroblasts. Acta Otolaryngol. Suppl 1998; 539:71-75.

51. Kohyama T, Takizawa H, Kawasaki S, Akiyama N, Sato M, Ito K. Fourteen-member macrolides inhibit interleukin- 8 release by human eosinophils from atopic donors. Antimicrob Agents Chemother. 1999; 43: 907-911.

52. Miyanohara T, Ushikai M, Matsune S, Ueno K, Katahira S, Kurono Y. Effects of clarithromycin on cultured human nasal epithelial cells and fibroblasts. Laryngoscope. 2000; 110: 126-131.

53. Cervin A. The anti-inflammatory effect of erythromycin and its derivatives, with special reference to nasal polyposis and chronic sinusitis. Acta Otolaryngol. 2001; 121: 83-92.

54. Leonard DW, Bolger WE. Topical antibiotic therapy for recalcitrant sinusitis. Laryngoscope. 1999; 109: 668-670.

55. Kamijyo A, Matsuzaki Z, Kikushima K, et al. Fosfomycin nebulizer therapy to chronic sinusitis. Auris Nasus Larynx. 2001; 28: 227-232.

56. Vaughan WC, Carvalho G. Use of nebulized antibiotics for acute infections in chronic sinusitis. Otolaryngol Head Neck Surg. 2002; 127: 558-568.

57. Scheinberg PA, Otsuji A. Nebulized antibiotics for the treatment of acute exacerbations of chronic rhinosinusitis. Ear Nose Throat J. 2002; 81: 648-652.

58. Sykes DA, Wilson R, Chan KL, Mackay IS, Cole PJ. Relative importance of antibiotic and improved clearance in topical treatment of chronic mucopurulent rhinosinusitis. A controlled study. Lancet. 1986; 2: 359-360.

59. Kobayashi T, Baba S. Topical use of antibiotics for paranasal sinusitis. Rhinol Suppl. 1992; 14: 77-81.

60. Desrosiers MY, Salas-Prato M. Treatment of chronic rhinosinusitis refractory to other treatments with topical antibiotic therapy delivered by means of a large-particle nebulizer: results of a controlled trial. Otolaryngol Head Neck Surg. 2001; 125: 265-269.

61. Videler WJ, van Drunen CM, Reitsma JB, Fokkens WJ. Nebulized bacitracin/colimycin: a treatment option in recalcitrant chronic rhinosinusitis with Staphylococcus aureus? A double-blind, randomized, placebo-controlled, cross-over pilot study. Rhinology. 2008; 46: 92-98.

62. Goh YH, Goode RL. Current status of topical nasal antimicrobial agents. Laryngoscope. 2000; 110: 875-880.

63. Elliott KA, Stringer SP. Evidence-based recommendations for antimicrobial nasal washes in chronic rhinosinusitis. Am J Rhinol. 2006; 20: 1-6.

64. Turlington EG. Chronic sclerosing nonsuppurative osteomyelitis. Trans Int Conf Oral Surg. 1973; 4: 120-124.

65. Videler WJ, Wreesmann VB, van der Meulen FW, Knegt PP, Fokkens WJ. Repetitive endoscopic sinus surgery failure: a role for radical surgery? Otolaryngol Head Neck Surg. 2006; 134: 586591.

66. Videler WJ, van Drunen CM, van der Meulen FW, Fokkens WJ. Radical surgery: Effect on quality of life and pain in chronic rhinosinusitis. Otolaryngol Head Neck Surg. 2007; 136: 261-267.

67. Rinia AB, Kostamo K, Ebbens FA, van Drunen CM, Fokkens 
WJ. Nasal polyposis: a cellular-based approach to answering questions. Allergy. 2007; 62: 348-358.

68. Rosenfeld RM, Andes D, Bhattacharyya N, et al. Clinical practice guideline: adult sinusitis. Otolaryngol Head Neck Surg. 2007; 137(3 Suppl): S1-31.

69. Fokkens W, Lund V, Mullol J. European position paper on rhinosinusitis and nasal polyps 2007. Rhinol. Suppl 2007; (20): 1-136.

70. Hounsfield GN. Computed medical imaging. Science. 1980; 210: 22-28.

71. Rahimi P, Wang CY, Stashenko P, Lee SK, Lorenzo JA, Graves DT. Monocyte chemoattractant protein-1 expression and monocyte recruitment in osseous inflammation in the mouse. Endocrinology. 1995; 136: 2752-2759.
W.J.M. Videler, MD

Department of Otorhinolaryngology Academic Medical Centre (AMC)

Meibergdreef 9

1105 AZ Amsterdam

the Netherlands

E-mail: W.J.Videler@amc.uva.nl

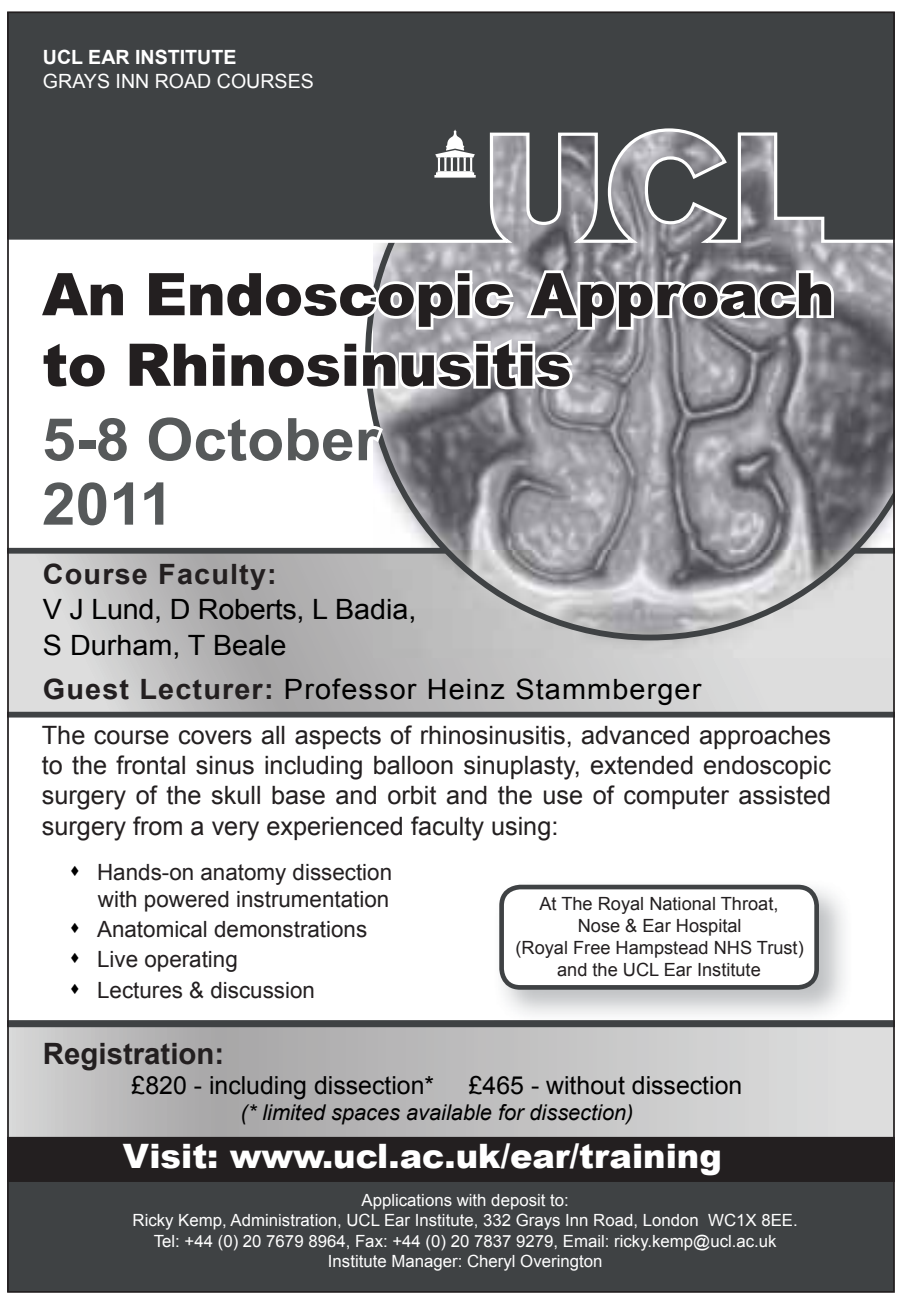

